\title{
Cultivo consorciado de batata-doce e milho pipoca: crescimento e produção das culturas
}

\author{
Marciel REDIN ${ }^{1 *}$, Scheila Andrieli Silveira BONES ${ }^{1}$, Jackson Eduardo Schmitt STEIN1, \\ Eduardo CANEPELLE ${ }^{1}$, Andersson Daniel STEFFLER ${ }^{1}$, Rodrigo ROTILI JUNIOR ${ }^{1}$, \\ Rafaela Fátima SERAFINI ${ }^{1}$, Patrique Jardel RADONS ${ }^{1}$
}

\author{
${ }^{1}$ Universidade Estadual do Rio Grande do Sul, Três Passos, Rio Grande do Sul, Brasil. \\ *E-mail: marcielredin@gmail.com \\ (Orcid: 0000-0003-4142-0522; 0000-0003-0698-8980; 0000-0003-3373-2550; 0000-0002-4029-5558; 0000-0003-1907- \\ 7510; 0000-0001-5962-414X; 0000-0001-5369-7006; 0000-0002-8721-1649)
}

Recebido em 03/09/2020; Aceito em 24/06/2021; Publicado em 12/07/2021.

\begin{abstract}
RESUMO: O objetivo foi avaliar o crescimento das plantas, produção de raízes de batata-doce (Ipomoea batatas) e grãos de milho pipoca (Zea mays) em sistema de cultivo solteiro e consorciado. Foram avaliadas quatro cultivares de batata-doce e uma de pipoca em blocos casualizados com três repetições em condições de campo. No cultivo solteiro, a pipoca e batata-doce foram espaçadas $75 \mathrm{~cm}$ entre linhas. No consorciado, o plantio da batata-doce foi no centro das entre linhas da pipoca. A adubação foi realizada com cama de frango. Aos 30, 60 e 90 dias foi avaliado o número de folhas, altura das plantas, diâmetro do colmo/baraços e comprimento de baraços. No florescimento foi determinada a matéria seca das plantas, na maturação fisiológica a produção de grãos da pipoca e aos 180, as raízes da batata-doce. Observou-se que a pipoca apresentou a maior produção de matéria seca, número de folhas, diâmetro de colmos e altura de plantas quando solteiro, as cultivares de batatadoce quando consorciadas menor produção de matéria seca e raízes, a produção de grãos de pipoca não apresentou diferença entres os sistemas de produção. O sistema consorciado de pipoca e batata-doce promove maior produção de matéria seca e produção de alimentos por área.
\end{abstract}

Palavras-chave: policultivos; sustentabilidade; agricultura familiar; Ipomoea batatas; Zea mays.

\section{Intercropped cultivation of sweet potatoes and popcorn: growth and production of crops}

\begin{abstract}
The objective was to evaluate plant growth, sweet potato productivity (Ipomoea batatas) and grains of popcorn (Zea mays) in single and intercropped systems. Four sweet potato cultivars and one popcorn in randomized blocks were evaluated with three replications in field conditions. In single cultivation, popcorn and sweet potatoes were spaced $75 \mathrm{~cm}$ between rows. In the intercropped, the sweet potato was in the center of between the lines of popcorn. Fertilization was carried out with chicken manure. At 30, 60 and 90 days, the number of leaves, plant height, stem/tiller diameter and tether length were evaluated. At flowering, the dry matter of the plants was determined, at physiological maturity the grain yield of the popcorn and at 180 , the roots of the sweet potato. It was observed that the popcorn showed the highest production of dry matter, number of leaves, stem diameter and plant height when single, sweet potato cultivars when intercropped, lower production of dry matter and roots, the productivity of popcorn grains there was no difference between the production systems. The intercroped system of popcorn and sweet potatoes promotes greater production of dry matter and food productivity per area.
\end{abstract}

Keywords: polyculture; sustainability; family farming; Ipomoea batatas; Zea mays.

\section{INTRODUÇÃO}

O modelo de produção em policultivos ou culturas consorciadas pode ser considerado um método antigo, porém seus princípios podem ser resgatados, com foco nos emergentes e atuais sistemas de produção sustentáveis. Diversos autores, apontam que o uso de policultivos é uma medida técnica entre as práticas recomendadas pela Agroecologia, que promove vantagens aos agricultores dispondo de maior diversidade de cultivos, diminuição dos riscos de perdas das colheitas por problemas adversos e redução das pragas no agroecossistema, com consequente aumento dos inimigos naturais que garantem um equilíbrio biológico no sistema (BRITO et al., 2016; ALTIERI, 2018;
ARAÚJO et al., 2019). Os policultivos, principalmente do gênero orgânico, são compreendidos como a implantação de duas ou mais culturas, dispostas na área cultivada em fileiras, plantadas em épocas iguais ou diferentes, sendo uma técnica utilizada para suprir as diferentes necessidades familiares (ALTIERI, 2012).

A principal razão pela qual agricultores utilizam policultivos é a possibilidade de obtenção de maiores produções na mesma área, equivalendo ou, na maioria das vezes, superior a uma área com sistema de monocultura (FERREIRA et al., 2014). Ainda a utilização da técnica de policultivos, nas suas diversas possibilidades de combinações 
de culturas, auxilia na qualidade do solo como, maior biodiversidade (BRITO et al., 2016; BETANCUR et al., 2018; maior cobertura do solo e, consequentemente, melhor controle sobre a erosão do solo (PANACHUKI et al., 2011), controle de plantas daninhas (RESENDE et al., 2016), interfere na decomposição dos resíduos culturais da mistura (AITA; GIACOMINI, 2003), maior eficiência de uso da terra (MOLINA-ANZURES et al., 2016) e maior aproveitamento de recursos renováveis, não renováveis e insumos utilizados nos cultivos (REZENDE et al., 2006; RIBEIRO et al., 2020). Por outro lado, a aplicação sequencial de culturas solteiras em áreas agrícolas repetidamente, aliada a movimentação das camadas do solo a adição errônea de nutrientes retirados do sistema, são pontos limitantes para sustentabilidade dos recursos naturais, produção, e consequentemente afeta a conservação deste recurso de suma importância para transição de sistemas agrícolas mais sustentáveis (BERTIN et al., 2005).

O equilíbrio do meio de cultivo, através da transição agroecológica possibilita restaura-se a resiliência e o vigor do agroecossistema, tornando a biodiversidade a principal técnica para evocar auto regulação e a sustentabilidade (ALTIERI, 2018). O manejo sustentável de um agroecossistema depende de seu nível de biodiversidade, riqueza de matéria orgânica, reposição adequada da fertilidade do solo, entre outros (GONZÁLEZ DE MOLINA; GUZMÁN CASADO, 2017), com isso, é fundamental o entendimento do uso da ocupação e papel do solo nos processos de transição agroecológica ou agriculturas de base ecológica. Nesse contexto, a agroecologia refere-se a estratégias e conhecimentos que vão além de aspectos tecnológicos ou agronômicos da produção, que necessita incorporar dimensões mais amplas e complexas, incluindo variáveis econômicas, sociais, ambientais, culturais, políticas e éticas da sustentabilidade (VARGAS et al., 2013). O agricultor familiar, costumeiramente, usa práticas que repetem aquelas usadas por seus antepassados e também aquelas que são observadas na natureza, os saberes culturais, através disso se observa a agrobiodiversidade existente em seus sistemas produtivos, por exemplo, os policultivos (RÓS et al., 2013; ALTIERI, 2018).

A batata-doce é uma espécie pertencente à família Convolvulaceae originária da América do Sul, possui diversas cultivares e ampla adaptação às condições climáticas do Brasil (MANTOVANI et al., 2018). O cultivo de batata-doce está intimamente ligado a agricultura familiar em cultivo consorciado com outras culturas através do preparo convencional do solo, sendo que a produção é utilizada totalmente para consumo próprio (RÓS et al., 2013). Da mesma forma, a cultura do milho, o tipo pipoca, espécie pertencente à família Poaceae é uma cultura amplamente difundida na agricultura familiar, pois apresenta importância alimentar e econômica tendo em vista o maior valor comercial comparado ao milho. O cultivo solteiro de batatadoce e milho pipoca em escala comercial é predominante, porém, o cultivo consorciado, ainda é muito utilizado, principalmente na agricultura familiar. No entanto, são poucos trabalhos que resgatam o cultivo dessas espécies em sistema consorciado e avaliam o desempenho agronômico desse sistema de produção, sobretudo com milho pipoca. Assim, o objetivo do trabalho foi avaliar o crescimento das plantas, produção de raízes de batata-doce e grãos de milho pipoca em sistemas solteiro e consorciado.

\section{MATERIAL E MÉTODOS}

O experimento foi realizado por dois anos experimentais, safras 2015/16 e 2016/17 em Bom Progresso, RS, em Latossolo Vermelho. A instalação do experimento, em cada ano experimental, ocorreu em outubro, disposto em blocos casualizados com três repetições, totalizando 27 parcelas experimentais de $6 \mathrm{~m}^{-2}(2 \times 3 \mathrm{~m})$. A semeadura do milho de variedade tipo pipoca crioulo no sistema solteiro e consorciado foi realizado em linhas, duas plantas por cova, com espaçamento de $20 \mathrm{~cm}$ entre plantas e $75 \mathrm{~cm}$ entre linhas. O plantio das cultivares de batata-doce, BRS Amélia, BRS Cuia, BRS Rubissol e Crioula, foi realizado com mudas de 3-4 folhas e de maneira similar ao milho pipoca crioulo, porém com espaçamento de 25 entre plantas na linha de semeadura. No plantio consorciado as mudas de batata-doce foram dispostas também em linhas no centro das entrelinhas do milho pipoca crioulo. A cultivar crioula de milho pipoca e batata-doce foram provenientes de agricultores locais, as outras cultivares de batata-doce da Embrapa Clima Temperado.

A adubação foi realizada conforme as necessidades do solo e estabelecidas conforme o Manual de Adubação e Calagem para estados do RS e de SC. A dose utilizada foi de $7000 \mathrm{~kg} / \mathrm{ha}(4,2 \mathrm{~kg} /$ parcela) de cama frango de quatro lotes, dividida em duas partes, metade na semeadura/plantio e a outra metade em cobertura após 45 após plantio/semeadura. As plantas daninhas foram controladas semanalmente com capinas manuais. Para controle de pragas e doenças foram realizadas aplicações quinzenais de óleo de neem. O experimento foi conduzido em condições naturais e sem irrigação. A figura 1 apresenta os dados de precipitação, temperatura média do ar e radiação solar durante o período do experimento.
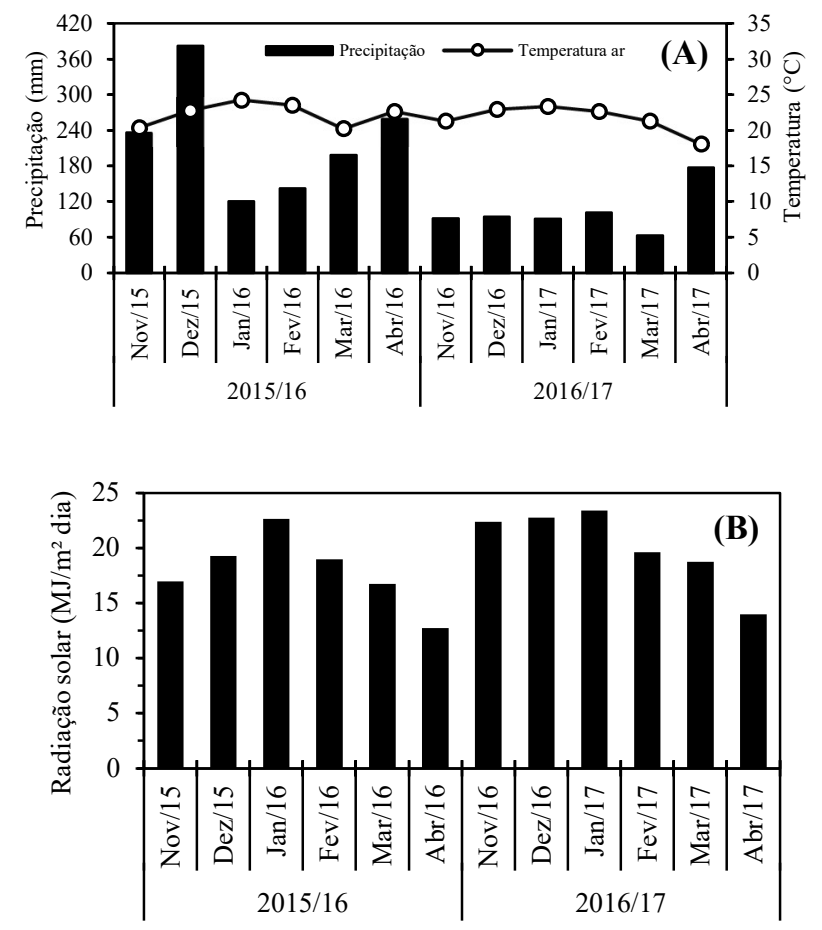

Figura 1. Precipitação, temperatura média do ar (A) e radiação solar (B) durante os dois anos experimentais.

Figure 1. Rainfall, mean air temperature (A) and solar radiation (B) during the two year experimental. 
No milho pipoca foi determinado a altura das plantas, número de folhas, diâmetro $(\varnothing)$ colmo e na batata-doce o número de folhas, comprimento e $\varnothing$ dos baraços aos 30, 60 e 90 dias. No início do experimento foram identificadas em todos os tratamentos seis plantas de cada cultura, nas quais sempre foram realizadas todas as avaliações. $\mathrm{O} \varnothing$ dos baraços foi determinado no baraço principal, na posição $20 \mathrm{~cm}$ a partir da base da planta, e $\varnothing$ do colmo do milho a $3 \mathrm{~cm}$ do nível do solo, ambos com paquímetro. A determinação da matéria seca das cultivares de batata-doce foi realizada no momento da floração com auxílio de um quadrado de madeira de $50 \mathrm{~cm} \times 50 \mathrm{~cm}$, disposto aleatoriamente no interior das parcelas e coletada a biomassa verde da área. A matéria seca das plantas de milho pipoca foi determinada no pleno florescimento com a coleta de dois segmentos de $75 \mathrm{~cm}$ cada. $\mathrm{O}$ material verde foi seco em estufa a $65^{\circ} \mathrm{C}$ até peso constante, e posteriormente determinada a matéria seca.

Para a determinação da produção de grãos do milho pipoca, foram colhidos na área útil de cada parcela experimental, manualmente, dois segmentos de linha de 75 $\mathrm{cm}$ cada. Após a colheita, as espigas foram debulhadas, os grãos secos ao ar, pesados e determinada a produção de grãos da cultura, corrigida para $13 \%$ de umidade. A análise do $\varnothing$, comprimento, número de fileiras e grãos por fileiras nas espigas, foi realizada em seis espigas de milho pipoca de cada tratamento. A produção das raízes de batata-doce foi determinada 180 dias após o plantio das mudas através da colheita manual das raízes de seis plantas por parcela, posteriormente lavadas em água corrente, secas ao ar e pesadas.

Os dados obtidos foram submetidos ao teste de variância (ANOVA) e as médias foram comparadas pelo teste de Tukey $5 \%$.

\section{RESULTADOS}

A análise dos dados não mostrou diferença entre os anos experimentais para as variáveis analisadas. A produção de matéria seca da parte aérea das plantas foi maior para a cultura do milho, sendo o cultivo solteiro com a maior produção de $4788 \mathrm{~kg} / \mathrm{ha}$ (Figura 2).

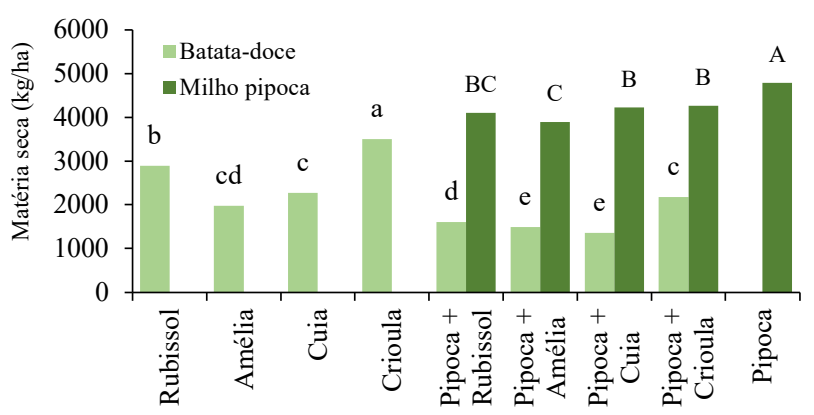

Figura 2. Produção de matéria seca da parte aérea das culturas de batata-doce e milho pipoca nos sistemas solteiros e consorciados. Barras seguidas de letras maiúsculas para milho pipoca e minúsculas para batata-doce, respectivamente, em sistemas solteiros e consorciados não diferem entre si pelo teste de Tukey $5 \%$.

Figure 2. Production of dry matter shoot of sweet potato and popcorn crops in single and intercropped systems. Bars followed by uppercase letters for popcorn and lowercase letters for sweet potatoes, respectively, in single and intercropped systems do not differ by the Tukey test $5 \%$.

No entanto, quando consorciado a produção de matéria seca do milho apresentou decréscimo médio de 13,93\%, com maior redução quando consorciado com batata cultivar Amélia, 17,73\%. Em relação a batata-doce, no sistema solteiro, as cultivares Crioula, Cuia e Amélia apresentaram a maior (3501 kg/ha) e as menores (2271 e $1978 \mathrm{~kg} / \mathrm{ha}$ ) produções de matéria seca, respectivamente, e média das cultivares $2661 \mathrm{~kg} / \mathrm{ha}$. Quando consorciadas, a cultivar Crioula apresentou a maior produção, $2176 \mathrm{~kg} / \mathrm{ha}$, e redução média das cultivares de $37,79 \%$ na produção de matéria seca. A adição total de matéria seca nos consórcios, variou de 5380 $\mathrm{kg} / \mathrm{ha}$ (Pipoca + Amélia) a $6439 \mathrm{~kg} / \mathrm{ha}$ (Pipoca + Crioula). O sistema consorciado apresentou a maior produção de matéria seca $17,11 \%$ e $53,93 \%$ em relação à média do cultivo solteiro de milho e cultivares de batata-doce, respectivamente.

A altura das plantas de milho pipoca sofreram interferência em seu crescimento quando a cultura da batatadoce foi adicionada no sistema de produção (Figura 3). $\mathrm{O}$ milho solteiro foi o tratamento que apresentou a maior altura das plantas aos 30, 60 e 90 dias, sendo superior a todos os tratamentos consorciados, entretanto os tratamentos consorciados não diferem entre si estatisticamente.

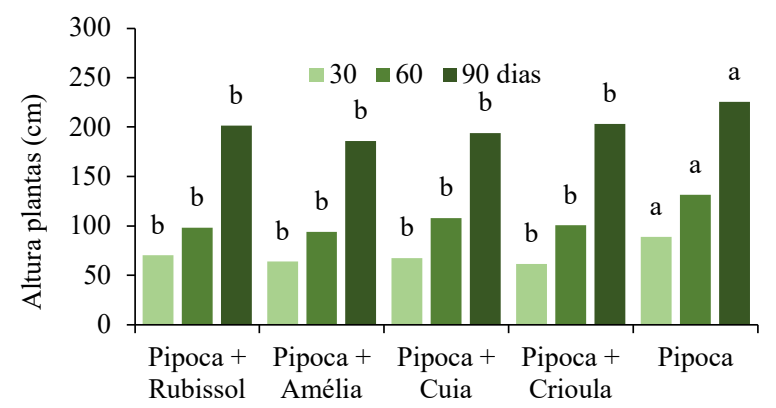

Figura 3. Altura da parte aérea do milho pipoca nos sistemas solteiros e consorciados. Barras seguidas de letras iguais para cada tempo de avaliação nos sistemas solteiros e consorciados não diferem entre si pelo teste de Tukey $5 \%$.

Figure 3. Height of the shoot of popcorn in single and intercropped systems. Bars followed by the same letters for each assessment time in single and intercropped systems do not differ by the Tukey test $5 \%$.

A cultura da batata-doce quando inserida no sistema do consórcio apresentou expressivo aumento no crescimento de seus baraços quando comparada ao seu cultivo solteiro, média de 80, 128 e $179 \mathrm{~cm}$, aos 30, 60 e 90 dias, respectivamente (Figura 4). A cultivar de batata-doce Crioula em consórcio apresentou o maior comprimento de baraços, $206 \mathrm{~cm}$ aos 90 dias de crescimento, entretanto, o consórcio das outras cultivares não diferiram entre si aos 30 e 60 dias. O comprimento de baraços, nas duas condições de cultivo foi proporcionalmente maior com o maior tempo após o plantio. As cultivares que apresentaram os menores crescimentos de seus baraços foram a Rubissol, Amélia aos 30 e 60 dias, respectivamente, Cuia e Crioula aos 90 dias, ambas em sistema solteiro.

O número de folhas planta ${ }^{-1}$ e $\varnothing$ dos colmos/baraços foi menor, intermediário e maior, para 30, 60 e 90 dias, respectivamente, para as culturas do milho pipoca e batatadoce nos sistemas solteiros e consorciados (Tabela 1). O número de folhas planta ${ }^{-1}, \varnothing$ de colmos e baraços foi superior nos cultivos solteiros de milho pipoca e batata-doce. A maior produção de folhas nos sistemas solteiros pode justificar a maior produção de matéria seca da parte aérea das plantas (Figura 1). 


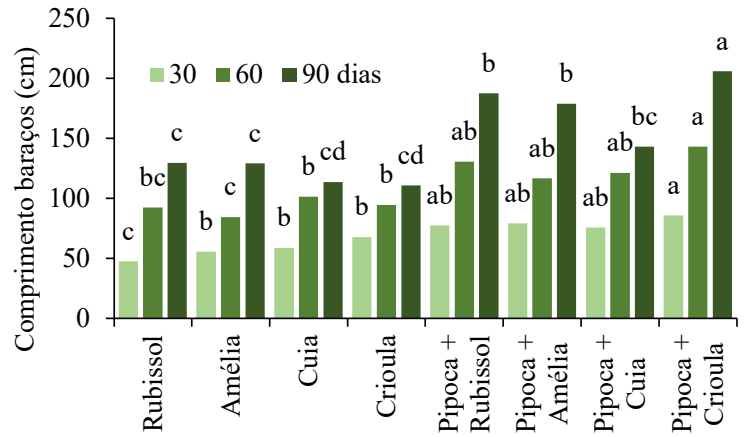

Figura 4. Comprimento dos baraços de batata-doce nos sistemas solteiros e consorciados. Barras seguidas de letras iguais para cada tempo de avaliação nos sistemas solteiros e consorciados não diferem entre si pelo teste de Tukey $5 \%$.

Figure 4. Length of sweet potato tethers in single and intercropped systems. Bars followed by the same letters for each assessment time in single and intercropped systems do not differ by the Tukey test $5 \%$.

Ainda, o milho pipoca cultivado solteiro apresentou maior altura de plantas (Figura 3) e maior $\varnothing$ do colmo (Tabela 1), no entanto não afetou a produção de grãos (Figura 2), comprimento, $\varnothing$, número de fileiras e grãos por fileiras nas espigas de milho (Tabela 2). Embora os baraços de batata-doce apresentaram maior crescimento no sistema consorciado $(30,23 \%)$, a menor produção de folhas, além do menor $\varnothing$ dos baraços pode explicar a menor produção de matéria seca (Figura 2). Já no sistema solteiro o $\varnothing$ do baraço da batata-doce foi maior (Tabela 1), assim como a produção de raízes da cultura (Figura 5).

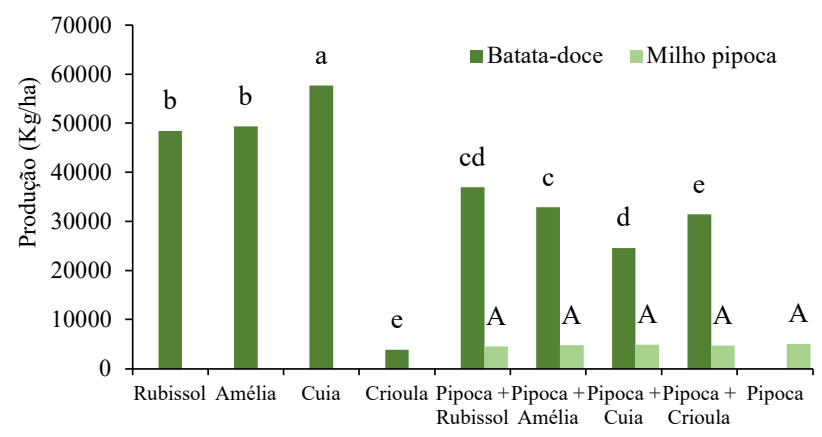

Higura ১. Produçao de raizes de batata-doce e graos de milho pipoca nos sistemas solteiros e consorciados. Barras seguidas de letras maiúsculas para milho pipoca e minúsculas para batata-doce, respectivamente, em sistemas solteiros e consorciados não diferem entre si pelo teste de Tukey $5 \%$.

Figure 5. Yield of sweet potato roots and popcorn grains in single and intercropped systems. Bars followed by uppercase letters for popcorn and lowercase letters for sweet potatoes, respectively, in single and intercropped systems do not differ by the Tukey test $5 \%$.

Tabela 1. Número de folhas planta-1 ${ }^{-1}$ diâmetro (Ø) do colmo/baraços do milho pipoca e batata-doce aos 30, 60 e 90 dias nos sistemas solteiros e consorciados.

Table 1. Number of plant ${ }^{-1}$ leaves, stem/tails diameter $(\varnothing)$ of popcorn and sweet potato corn at 30, 60 and 90 days in single and intercropped systems.

\begin{tabular}{|c|c|c|c|c|c|c|c|c|c|c|c|c|c|}
\hline \multirow{3}{*}{ Tratamentos } & \multicolumn{7}{|c|}{ Número de folhas } & \multicolumn{6}{|c|}{$\varnothing$ colmo/baraços } \\
\hline & & \multicolumn{3}{|c|}{ Milho pipoca } & \multicolumn{3}{|c|}{ Batata-doce } & \multicolumn{3}{|c|}{ Milho pipoca $(\mathrm{cm})$} & \multicolumn{3}{|c|}{ Batata-doce $(\mathrm{cm})$} \\
\hline & Dias & 30 & 60 & 90 & 30 & 60 & 90 & 30 & 60 & 90 & 30 & 60 & 90 \\
\hline Pipoca & & $8 \mathrm{a}^{*}$ & $11 \mathrm{a}$ & $17 \mathrm{a}$ & & & & 1,28 ns & 1,34 ns & $1,63 \mathrm{a}$ & & & \\
\hline Pipoca + Crioula & & $7 \mathrm{~b}$ & $9 \mathrm{~b}$ & $15 \mathrm{~b}$ & $17 \mathrm{c}$ & $28 \mathrm{c}$ & $42 \mathrm{c}$ & 1,21 & 1,27 & $1,40 \mathrm{~b}$ & $0,23 \mathrm{~b}$ & $0,31 \mathrm{bc}$ & $0,65 \mathrm{ba}$ \\
\hline Pipoca + Rubissol & & $6 \mathrm{bc}$ & $8 \mathrm{bc}$ & $13 \mathrm{~b}$ & $17 \mathrm{c}$ & $25 \mathrm{c}$ & $35 \mathrm{c}$ & 1,17 & 1,35 & $1,45 \mathrm{~b}$ & $0,19 \mathrm{c}$ & $0,45 \mathrm{~b}$ & $0,52 \mathrm{~b}$ \\
\hline Pipoca + Amélia & & $5 \mathrm{c}$ & $7 \mathrm{c}$ & $11 \mathrm{c}$ & $19 \mathrm{c}$ & $24 \mathrm{c}$ & $33 \mathrm{c}$ & 1,05 & 1,14 & $1,19 \mathrm{c}$ & $0,23 \mathrm{~b}$ & $0,43 \mathrm{~b}$ & $0,53 \mathrm{~b}$ \\
\hline Pipoca + Cuia & & $7 \mathrm{~b}$ & $9 \mathrm{~b}$ & $14 \mathrm{~b}$ & $16 \mathrm{c}$ & $23 \mathrm{c}$ & $30 \mathrm{c}$ & 1,30 & 1,37 & $1,50 \mathrm{~b}$ & $0,21 \mathrm{bc}$ & $0,38 \mathrm{~b}$ & $0,41 \mathrm{c}$ \\
\hline Rubissol & & & & & $30 \mathrm{~b}$ & $44 \mathrm{~b}$ & $51 \mathrm{~b}$ & & & & $0,37 \mathrm{a}$ & $0,58 \mathrm{a}$ & $0,83 \mathrm{a}$ \\
\hline Amélia & & & & & $26 \mathrm{~b}$ & $37 \mathrm{~b}$ & $50 \mathrm{~b}$ & & & & $0,30 \mathrm{ab}$ & $0,52 \mathrm{a}$ & $0,81 \mathrm{a}$ \\
\hline Cuia & & & & & $23 \mathrm{bc}$ & $41 \mathrm{~b}$ & $56 \mathrm{~b}$ & & & & $0,34 \mathrm{a}$ & $0,55 \mathrm{a}$ & $0,75 \mathrm{a}$ \\
\hline Crioula & & & & & $39 \mathrm{a}$ & $57 \mathrm{a}$ & $75 \mathrm{a}$ & & & & $0,42 \mathrm{a}$ & $0,79 \mathrm{a}$ & $0,90 \mathrm{a}$ \\
\hline $\mathrm{CV}(\%)$ & & 10,3 & 8,7 & 21,5 & 6,5 & 24,4 & 7,8 & 28,2 & 17,5 & 12,9 & 9,1 & 6,3 & 15,2 \\
\hline
\end{tabular}

* Médias na coluna não são estatisticamente diferentes pelo teste de Tukey a $5 \%$ de probabilidade. ${ }^{\text {ns }}$ não significativo.

A produção de raízes de batata-doce é superior quando cultivadas solteiras, sendo a cultivar Cuia e Crioula, 57668 e $3879 \mathrm{~kg} / \mathrm{ha}$, a maior e menor produção, respectivamente (Figura 5). No sistema consorciado, houve redução média de 39,85\%, sendo Pipoca + Cuia com maior redução (53,9\%) e produção média das cultivares em consórcio de $39827 \mathrm{~kg} / \mathrm{ha}$. Embora o sistema consorciado afetou negativamente a produção de raízes de batata-doce, o consórcio não afetou a produção de grãos do milho pipoca (média de 4759 kg/ha).
A análise nas espigas de milho pipoca, ou seja, diâmetro de espiga, comprimento, número de grãos e fileiras por espiga, não apresentou diferença entre os sistemas solteiro e consorciados de batata-doce e milho pipoca (Tabela 2). Da mesma forma que observado para a produção de grãos de milho pipoca (Figura 5), não houve diferença nos parâmetros de qualidade das espigas, assim, não sofrendo influência pela presença em consórcio com a cultura da batata-doce.

Tabela 2. Diâmetro (Ø), comprimento, número de fileiras e grãos por fileira por espigas do milho pipoca nos sistemas solteiros e consorciados.

Table 2. Diameter $(\varnothing)$, length, number of rows and grains per row per ears of popcorn in single and intercropped systems.

\begin{tabular}{lllll}
\hline Tratamentos & $\varnothing$ espiga $(\mathrm{cm})$ & Comprimento $(\mathrm{cm})$ & Fileiras $\left(\mathrm{n}^{\circ}\right)$ & $\mathrm{Grãos}^{\mathrm{f}}$ fileira $\left(\mathrm{n}^{\mathrm{O}}\right)$ \\
\hline Pipoca & $3,4^{\mathrm{ns}}$ & 13,6 ns & $12,3^{\mathrm{ns}}$ & $22,6^{\mathrm{ns}}$ \\
Pipoca + Crioula & 3,7 & 15,4 & 13,7 & 24,3 \\
Pipoca + Rubissol & 3,4 & 13,9 & 12,8 & 17,9 \\
Pipoca + Amélia & 3,3 & 11,5 & 12,2 & 17,1 \\
Pipoca + Cuia & 3,5 & 13,1 & 12,5 & 19,7 \\
\hline CV $(\%)$ & 12,66 & 42,62 & 16,05 & 36,37 \\
\hline
\end{tabular}

ns não significativo. 


\section{DISCUSSÃO}

A não diferença entre os anos experimentais mostra que as culturas da batata-doce e milho pipoca crioulo são pouco influenciadas por fatores climáticos, mostrando estabilidade de cultivo devido suas rusticidades (MANTOVANI et al., 2018). Em relação a produção de matéria seca das plantas de milho, Chioderoli et al. (2012) observaram maior produção das plantas de milho em sistema solteiro, comparado aos sistemas consorciados com batata-doce $(13,95 \%)$. Figueiredo (2012), também encontrou dados similares para dez cultivares de batata-doce, com produções de matéria seca que variam de 3,05 a 4,95 ton $\mathrm{ha}^{-1}$. Donato et al. (2020) observaram valores médios de 6,6 ton ha ${ }^{-1}$ de matéria seca da parte aérea para dez cultivares de batata-doce.

A menor produção de matéria seca das plantas de batatadoce no sistema consorciado pode estar relacionado ao maior sombreamento provocado pelas plantas de milho. Wang et al. (2011), em experimento com efeitos do estresse por sombreamento também observaram redução significativa na produção de matéria seca das plantas de batata-doce em comparação com o controle sem sombreamento. Já para as plantas de milho, a redução pode ser atribuída também a maior competição por espaço, água, nutrientes do solo e radiação solar. Pariz et al. (2011), também observaram redução, além da produção de grãos, da produção de matéria seca das plantas de milho cultivadas em consórcio com espécies de braquiárias, tanto em semeadura a lanço ou na linha do consórcio com o milho.

De acordo com Chioderoli et al. (2012), sistemas que proporcionam maiores produção de matéria seca, apresentam uma série de benéficos para o solo e para as culturas em sucessão. Bentancur et al. (2018), descreveram os benefícios mútuos entre as culturas quando consorciadas, por exemplo, no consórcio de milho, feijão e abobrinha, onde o milho tem como principal benefício, a criação de um microambiente favorável para as culturas, quebrando ciclo de pragas, e a abobrinha funcionando como um isolante do solo, evitando, entre outros, a germinação de plantas daninhas. Nos sistemas de consórcios o aproveitamento dos nutrientes, água e radiação solar pelas plantas são otimizados. De acordo com Bentancur et al. (2018), quando duas plantas crescem juntas, existe influência mútua, e a combinação de culturas gera melhores rendimentos, sendo mais eficiente no uso de recursos econômicos e ambientais (água, luz e nutrientes), o que se reflete na valoração do meio ambiente, economia de recursos, e por fim, favorecendo o bem-estar de famílias camponesas, pois, aproveitam de maneira mais eficiente as áreas de cultivo.

Culturas ou sistemas de cultivos que apresentam maior produção de matéria seca promovem uma série de benefícios principalmente aqueles relacionados ao solo. As culturas quando consorciadas além de auxiliarem na promoção e manutenção da biota do solo garantem uma melhor agregação física, pois, são dois tipos de raízes de plantas de diferentes famílias botânicas interagindo na mesma área de solo. Em cultivos solteiros de batata-doce ou milho pipoca, a qualidade química dos resíduos culturais é baixa, no entanto, quando consorciados forma-se uma mistura mais equilibrada e amplia-se a qualidade dos resíduos, como por exemplo, altera a relação $\mathrm{C} / \mathrm{N}$ dos resíduos. Os diferentes tipos de resíduos, apresentam diferentes composições químicas que estão diretamente ligados ao potencial de decomposição e ciclagem de nutrientes (REDIN et al., 2018). Os resíduos de milho, com maior quantidade de componentes recalcitrantes, a decomposição é mais lenta, se comparado aos de batatadoce, assim, decomposição intermediária na mistura dos resíduos. Resíduos mais ricos em nitrogênio ou em misturas equilibradas e diversificadas, aliados à sua quantidade, atuam diretamente na biologia do solo, com o aumento da atividade, número de indivíduos e espécies favorecidas pela disponibilidade de alimento, condições de temperatura e umidade do solo, criadas pela cobertura do solo. Araújo et al. (2019), ressaltam maior atividade biológica na camada superficial no solo dos cultivos, incluindo os consórcios, diminuindo rapidamente em camadas mais profundas do solo, mostrando assim, a importância dos resíduos de superfície do solo.

A redução do crescimento das plantas de milho pipoca quando consorciada com batata-doce pode ser associado a maior produção de matéria seca de parte aérea da pipoca, porém quando cultivado em sistema solteiro (Figura 2). Neto et al. (2012), também verificaram que o milho pipoca quando consorciado com feijão apresentou redução significativa na altura de plantas. O maior crescimento dos baraços de batatadoce no sistema consorciado, pode estar relacionado ao sombreamento das plantas pelo milho pipoca, que provocou as plantas a buscarem radiação solar mais distante, fora da área de sombreamento. Em estudo de Martuscello et al. (2009), porém para diferentes pastagens, observaram que em condições de sombreamento as plantas tendem a alongar colmos e folhas como forma de buscar exposição à luz, o que aumenta a altura das plantas.

A maior produção de baraços de batata-doce é benéfica no quesito de cobertura do solo, impedindo o contato direto de gotas de água evitando a sua desestruturação e erosão, manutenção da umidade do solo, diminuição da amplitude térmica e favorecimento da biologia do solo. Cardoso et al. (2012), ao estudarem o efeito de proteção de solo, com o uso de plantas de cobertura, encontrou no feijão de porco (Canavalia ensiformis), planta de estrutura foliar muito parecida com a batata-doce, maior capacidade de diminuição dos impactos das gotas da chuva, diminuindo a rugosidade do solo, se comparada a crotalária juncea (Crotalaria juncea), planta de similar arquitetura ao milho, e por consequência, foi menor o carreamento das partículas do solo. A maior produção de matéria seca associado ao comprimento dos baraços, além dos benefícios para o solo e culturas em sucessão, de acordo com Donato et al. (2020); Andrade Junior et al. (2020), são desejados para maior produção de forragem para alimentação animal.

O maior número de folhas/planta ${ }^{-1}$ e $\varnothing$ dos colmos/baraços observado aos 90 dias está relacionado ao crescimento das plantas que têm a tendência de aumentar o seu desenvolvimento com o tempo de cultivo. De acordo com Caratti et al. (2016), quando a planta busca um ambiente livre de competição, cresce em altura, no entanto, o aumento da massa foliar é reduzido, com menos galhos e folhas mais finas, já que a planta investe grande parte de seus foto assimilados para alongar o caule. Ceratti et al. (2016) quando analisou a competição, porém entre plantas de milho e de soja, observou a baixa produção de matéria seca das raízes, da área foliar e desenvolvimento reduzido do diâmetro de caule da soja devido aos altos níveis de competição com as plantas de milho, independentemente da condição da competição. Negrini et al. (2010) observaram no consórcio entre alface (Lactuca sativa) e feijão caupi (Vigna unguiculata), a 
menor produção de folhas na cultura da alface, devido à grande produção de biomassa e a competição por luz. Rezende et al. (2006), verificaram redução do diâmetro da alface, no número de folhas e aumento na altura de plantas, quando consorciada com pimentão e repolho, o autor remete provavelmente, à maior competição interespecífica, principalmente com relação à luz, proporcionado pelo sombreamento exercido das folhas do repolho sobre a alface. Segundo Ceratti et al. (2016), quando a competição ocorre no solo, a quantidade de água e nutrientes disponíveis para o sistema radicular é limitado, ocasionando o desenvolvimento reduzido da parte aérea das plantas.

Donato et al. (2020) observaram menores produções de raízes de batata-doce conduzido somente em sistema solteiro com média de 16,6 ton hä ${ }^{-1}$. Rós; São João (2016), constataram que em consórcio de batata-doce e mandioca, a batata-doce apresenta maior produção de raízes quando em sistema solteiro. Nespoli et al. (2017) observaram que durante o consórcio de alface + milho verde, que a cultura da alface produz mais quando solteira, e que a produção de milho verde não é influenciada pelo consórcio. $O$ milho, por ser uma espécie $\mathrm{C} 4$, apresenta menor competição por água e gás carbônico do que o feijão, que é uma espécie C3, não caracterizando-se por perdas significativas, quando submetido ao consórcio com o feijão, contrariamente ao que ocorre com o feijão (NETO et al., 2012). Embora, poderá ocorrer perdas de produção para alguma cultura em sistema consorciado, segundo Nespoli et al. (2017), devido a característica de melhor aproveitamento da área produtiva, da adubação, da irrigação e da mão de obra, isso pode ser um incentivo à adoção da técnica dos cultivos consorciados.

Neto et al. (2012), em experimento com milho pipoca e feijão consorciados, evidenciou que o milho não apresenta oscilações na produção e parâmetros de rendimento de grãos, havendo a manutenção da produção do cultivo solteiro. Scotta et al. (2018), que consorciaram milho com brachiária (Brachiaria decumbens) ou feijão guandu (Cajanus cajan), observaram que nenhuma das variáveis nas espigas de milho foram afetadas com o plantio consorciado das culturas.

Embora os sistemas solteiros de batata-doce e milho pipoca apresentaram-se no final menos produtivos (Figura 5), no entanto, quando consorciados aumenta a produção total de matéria seca (Figura 2), comprimento de baraços (Figura 4) e pode-se manter a produção e qualidade de grãos do milho pipoca, além de trazer, por exemplo, aumento da renda por área e maior segurança da produção. Segundo Bentancur et al. (2018), evidenciam o benefício dos consórcios pela maior produção por área com policultura do que uma equivalente com monocultura. Rós; São João (2016), também relatam que os consórcios são mais produtivos que os cultivos solteiros. Segundo Neto et al. (2012), concluíram que no consórcio de milho + feijão o índice de equivalência da terra, são de 50 a $91 \%$ mais efetivos que os monocultivos.

Quando plantas são consorciadas, cada espécie apresenta um serviço ecossistêmico no meio em que está inserida. Betancur et al. (2018), quando consorciaram três plantas evidenciaram que a associação permitiu a expressão do serviço ecológico, fortalecendo o aumento da biodiversidade e a segurança alimentar com a utilização dos recursos locais, em que o conhecimento tradicional foi adicionado a ciência moderna. Oliveira et al. (2017) trabalharam com policultivos, porém para verduras, e seus resultados tiveram aspectos positivos para os índices agronômicos/biológicos, confirmando o melhor uso de recursos ambientais por hortícolas em associação. Ribeiro et al. (2020) também observaram maior produção de feijão caupi quando consorciado com beterraba. Molina-Anzures et al. (2016) observaram que os sistemas consorciados duas ou três espécies de plantas interagem com o ambiente e podem duplicar ou até mesmo triplicar a produção por unidade de área se comparado com as monoculturas, apresentando uma maior eficiência produtiva. Rezende et al. (2006), observaram superioridade de 92 a $164 \%$ na produção de alimento por área dos consórcios sobre os monocultivos, isso demonstra a viabilidade dos policultivos e maior eficiência do uso da terra.

Embora os sistemas de cultivo consorciados são pouco evidenciados, comparado aos monocultivos, são uma excelente alternativa de cultivo, principalmente para a agricultura familiar ou pequenas propriedades rurais. Ainda, assim, promovem a sustentabilidade produtiva, através do uso eficiente da terra e social ao introduzir independência produtiva e financeira, ao se produzir mais em um menor espaço e com baixo custo e ambiental, ao se utilizar de forma mais consciente os recursos naturais.

\section{CONCLUSÕES}

O sistema consorciado de milho pipoca e batata-doce, embora tem efeito negativo na produção de matéria seca e altura de plantas, não afeta a produção de grãos de milho pipoca.

O cultivo consorciado promove maior crescimento dos baraços, porém menor $\varnothing$ dos baraços, produção de folhas e raízes de batata-doce quando consorciada com milho pipoca.

O sistema consorciado de milho pipoca e batata-doce promove maior produção final de matéria seca e de alimentos, raízes de batata-doce e milho pipoca por unidade de área.

\section{AGRADECIMENTOS}

Este trabalho contou com financiamento $\mathrm{CNPq}_{\mathrm{e}}$ UERGS, por meio de bolsas de iniciação científica modalidade $\mathrm{CNPq}$ e INICIE/UERGS pelos Editais PROPPG 006/2015 e 011/2015, respectivamente.

\section{REFERÊNCIAS}

AITA, C.; GIACOMINI, S. J. Decomposição e liberação de nitrogênio de resíduos culturais de plantas de cobertura de solo solteiras e consorciadas. Revista Brasileira de Ciência do Solo, Viçosa, v. 27, n. 4, p. 601-612, 2003. DOI: 06832003000400004

ALTIERI, M. Agroecologia, agricultura camponesa e soberania alimentar. Revista Nera, Presidente Prudente, n. 16, v. 13, p. 22-32, 2012.

ALTIERI, M. A. Agroecology: the science of sustainable agriculture. 2 ed. Boca Raton: CRC Press, 2018. 448p.

ANDRADE JÚNIOR, V. C.; DONATO, L. M. S.; AZEVEDO, A. M.; GUIMARÃES, A. G.; BRITO, O. G.; OLIVEIRA, D. M.; MEDINA, A. J.; SILVA, L. R. Association between agronomic characters and hay quality of sweet potato branches. Horticultura Brasileira, Brasília, v. 38, n. 1, p. 27-32, 2020. DOI: http://dx.doi.org/10.1590/S0102-053620200104

ARAÚJO, T. S.; GALLO, A. S.; ARAÚJO, F. S.; SANTOS, L. C.; GUIMARÃES, N. F.; SILVA, R. F. Biomassa e atividade microbiana em solo cultivado com milho

Nativa, Sinop, v. 9, n. 3, p. 286-293, mai./jun. 2021. 
consorciado com leguminosas de cobertura. Revista de Ciências Agrárias, Lisboa, v. 42, n. 2, p. 51-60, 2019. DOI: http://dx.doi.org/10.19084/rca.15433

BERTIN, E. G.; ANDRIOLI, I.; CENTURION, J. F. Plantas de cobertura em pré-safra ao milho em plantio direto. Acta Scientiarum. Agronomy, Maringá, v. 27, n. 3, p. 379-386, $2005 . \quad$ DOI: http://dx.doi.org/10.4025/actasciagron.v27i3.1393

BETANCUR, L. M. G.; GIRÓN, S. M. M.; BETANCUR, L. F. R. La milpa como alternativa de conversión agroecológica de sistemas agrícolas convencionales de frijol (Phaseolus vulgaris), en el municipio El Carmen de Viboral, Colombia. Idesia, Arica, v. 36, n. 1, p. 123-131, 2018. DOI: http://dx.doi.org/10.4067/S071834292018000100123

BRITO, M. F.; TSUjIgUSHi, B. P.; OTSUBO, A. A., SILVA, R. F.; MERCANTE, F. M. Diversidade da fauna edáfica e epigeica de invertebrados em consórcio de mandioca com adubos verdes. Pesquisa Agropecuária Brasileira, Brasília, v. 51, n. 3, p. 253-260, 2016. DOI: http://dx.doi.org/10.1590/S0100-204X2016000300007

CARATTI, F. C.; LAMEGO, F. P.; SILVA, J. D. G.; GARCIA, J. R.; AGOSTINETTO, D. Partitioning of competition for resources between soybean and corn as competitor plant. Planta Daninha, Viçosa, v. 34, n. 4, p. 657-665, 2016. DOI: https://doi.org/10.1590/s010083582016340400005

CARDOSO, D. P.; SILVA, M. L. N.; CARVALHO, G. J.; FREITAS, D. A. F.; AVANZI, J. C. Plantas de cobertura no controle das perdas de solo, água e nutrientes por erosão hídrica. Revista Brasileira de Engenharia Agrícola e Ambiental, Campina Grande, v. 16, n. 6, p. 632-638, 2012. DOI: http://dx.doi.org/10.1590/S141543662012000600007

CHIODEROLI, C. A.; MELLO, L. M. M.; HOLANDA, H. V.; FURLANI, C. E. A.; GRIGOLLI, P. J.; SILVA, J. O. R.; CESARIN, A. L. Consórcio de Urochloas com milho em sistema plantio direto. Ciência Rural, Santa Maria, v. 42, n. 10, p. 1804-1810, 2012. DOI: https://doi.org/10.1590/S0103-84782012005000073

DONATO, L. M. S.; JUNIOR, V. C. A.; BRITO, O. G.; FIALHO, C. M. T.; SILVA, A. J. M.; AZEVEDO, A. M. Uso de ramas de batata-doce para produção de feno. Ciência Animal Brasileira, Goiânia, v. 21, e-53493, 2020. DOI: https://doi.org/10.1590/1809-6891v21e53493

FERREIRA, E. A.; SILVA, D. V.; BRAGA, R. R; OLIVEIRA, M. C.; PEREIRA, G. A. M.; SANTOS, J. B.; SEDIYAMA, T. Crescimento inicial da cultura da mandioca em sistema de policultivo. Scientia Agraria Paranaensis, Marechal Cândido Rondon, v. 13, n. 3, p. 219-226, 2014. DOI: 10.18188/19831471/sap.v13n3p219-226

FIGUEIREDO, J. A.; JÚNIOR V. C. A.; PEREIRA R. C.; RIBEIRO, K. G.; VIANA, D. J. S.; NEIVA, I. P. Avaliação de silagens de ramas de batata-doce. Horticultura Brasileira, Brasília, v. 30, n. 4, p. 708-712, 2012. DOI: https://doi.org/10.1590/S010205362012000400024

GONZÁLEZ DE MOLINA M.; GUZMÁN CASADO G. I. Agroecology and Ecological Intensification. A Discussion from a Metabolic Point of View. Sustainability, v. 9, n. 1, p. 1-19, 2017. DOI: $10.3390 /$ su9010086
MANTOVANI, E. C.; DELAZARI, F. T.; DIAS, L. D.; ASSIS, I. R.; VIEIRA, G. H. S.; LANDIM, F. M. Produtividade e uso eficiente da água de duas cultivares de batata-doce em função de lâmina de irrigação. Horticultura Brasileira, Brasília, v. 31, n. 4, p. 602-606, 2018. DOI: https://doi.org/10.1590/S010205362013000400015.

MARTUSCELLO, J. A.; JANK, L.; NETO, M. M. G.; LAURA, V. A.; CUNHA, D. N. F. V. Produção de gramíneas do gênero Brachiaria sob níveis de sombreamento. Revista Brasileira Zootecnia, Viçosa, v. 38 , n. 7 , p. $1183-1190$, 2009. DOI: https://doi.org/10.1590/S1516-35982009000700004

MOLINA-ANZURES, M. F.; CHÁVEZ-SERVIA, J. L.; GIL-MUÑOZ, A.; LÓPEZ, P. A.; HERNÁNDEZROMERO, E.; ORTIZ-TORRES, E. Eficiencias productivas de asociaciones de maíz, frijol y calabaza (Curcurbita pepo L.), intercaladas con árboles frutales. Revista Internacional de Botânica Experimental, Nevada, v. 85, n. 1, p. 36-50, 2016.

NEGRINI, A. C. A.; MELO, P. C. T.; AMBROSANO, E. J.; SAKAI, R. H.; SCHAMMASS, E. A.; ROSSI, F. 2010. Performance of lettuce in sole cropping and intercropping with green manures. Horticultura Brasileira, Brasília, v. 28, n. 1, p. 58-63, 2010. DOI: https://doi.org/10.1590/S0102-05362010000100011

NESPOLI, A.; JÚNIOR, S. S.; DALLACORT, R. PURQUERI, L. F. V. Consórcio de alface e milho verde sobre cobertura viva e morta em plantio direto. Horticultura Brasileira Brasília, v. 35, n. 3, p. 453-457, 2017. DOI: https://doi.org/10.1590/s0102053620170323

NETO, A. L. V.; HEINZ, R.; GONÇALVES, M. C.; CORREIA, A. M. P.; MOTA, L. H. S.; ARAÚJO, W. D. Milho pipoca consorciado com feijão em diferentes arranjos de plantas. Pesquisa Agropecuária Tropical, Goiânia, v. 42, n. 1, p. 28-33, 2012. DOI: http://dx.doi.org/10.1590/S1983-40632012000100004

OLIVEIRA, L. A. A.; NETO, F. B.; JÚNIOR, A. P. B.; SILVA, M. L.; OLIVEIRA, O. F. N.; LIMA, J. S. S. Agroeconomic efficiency of polycultures of arugula-carrotlettuce fertilized with roostertree at diferente population density proportions. Revista Brasileira de Engenharia Agrícola e Ambiental, Campina Grande, v. 21, n. 11, p. 791-797, 2017. DOI: https://doi.org/10.1590/18071929/agriambi.v21n11p791-797

PANACHUKI, E.; BERTOL, I.; SOBRINHO, T. A; OLIVEIRA, P. T. S.; RODRIGUES, D. B. B. Perdas de solo e de água e infiltração de água em latossolo vermelho sob sistemas de manejo. Revista Brasileira de Ciência do Solo, Viçosa, v. 35, p. 1777-1785, 2011. DOI: https://doi.org/10.1590/S0100-06832011000500032

PARIZ, C. M.; ANDREOTTI, M.; AZENHA, M. V.; BERGAMASCHINE, A. F.; MELLO, L. M. M.; LIMA, R. C. Produtividade de grãos de milho e massa seca de braquiárias em consórcio no sistema de integração lavoura-pecuária. Ciência Rural, Santa Maria, v. 41, n. 5, p. 875-882, 2011. DOI: https://doi.org/10.1590/S010384782011000500023

REDIN, M.; SYLVIE, A.; AITA, C.; CHAVES, B.; PFEIFER, I. C; BASTOS, L. M.; PILECCO, G. E; GIACOMINI, S. J. Root and shoot contribution to carbon and nitrogen inputs in the topsoil layer in notillage crop systems under subtropical conditions. 
Revista Brasileira de Ciência do Solo, Viçosa, v. 42, n. 1, p. 1-16, $2018 . \quad$ DOI: https://doi.org/10.1590/18069657rbcs20170355

RESENDE, B. P. M.; JAKELAITIS, A., TAVARES, C., MARANGONI, R.; RIBEIRO, C.P. Consórcio de sorgo com espécies forrageiras. Revista AgroAmbiente Online, Boa Vista, v. 10, n. 1, p. 57-64, 2016. DOI: http://dx.doi.org/10.18227/1982-8470ragro.v10i1.3052

REZENDE, B. L. A; FILHO, A. B. C.; FELTRIM, A. L.; COSTA, C. C.; BARBOSA, J. C. Viabilidade da consorciação de pimentão com repolho, rúcula, alface e rabanete. Horticultura Brasileira, Brasília, v. 24, n. 1, p. 36-41, 2006. DOI: http://dx.doi.org/10.1590/S010205362006000100008

RIBEIRO, J. R. S; BEZERRA NETO, F.; LIMA, J. S. S.; CHAVES, A. P.; SILVA, J. N.; SANTOS, E. C.; NUNES, R. L. C. Production efficiency in cultivar combinations of beet and cowpea. Horticultura Brasileira, Brasília, v. 38, n. 1, p. 445-453, 2020. DOI: https://doi.org/10.1590/s0102-0536202004017

RÓS, A. B.; FILHO, J. T.; BARBOSA, G. M. C. Produtividade da cultura da batata-doce em diferentes sistemas de preparo do solo. Bragantia, Campinas, v. 72, n. 2, p. 140-145, 2013. DOI: https://doi.org/10.1590/S0006-87052013000200005

RÓS, A. B.; SÃO JOÃO, R. E. Desempenho agronômico e uso eficiente da terra em arranjos de plantas de mandioca e batata-doce. Revista Ceres, Viçosa, v. 63 n. 4, p. $517-$ 522, 2016. DOI: https://doi.org/10.1590/0034737X201663040012

SCOTTA, R. G. M.; FILHO, G. C. M.; PELUZIO, J. M.; CARVALHO, E. V.; DOTTO, M. A.; AFFÉRRI, F. S. Efeitos de adubação nitrogenada de cobertura em milho consorciado. Revista Brasileira de Agropecuária Sustentável, Viçosa, v. 8, n. 3, p. 73-80, 2018. DOI: https://doi.org/10.21206/rbas.v8i3.2995

VARGAS, D. L.; FONTOURA, A. F.; WIZNIEWSKY, J. G. Agroecologia: base da sustentabilidade dos agroecossistemas. Geografia Ensino e Pesquisa, Santa Maria, v. 17, n. 1, p. 173-180, 2013. DOI: http:/ /dx.doi.org/10.5902/22364994/8748

WANG, Q.; FUYUN, H.; BAOQING, W. Effects of shading stress on qualities of purple sweetpotato storage roots. Scientia Agricultura Sinica, v. 44, n. 1, p. 192 200, 2011. 